\title{
Process simulation and comparison of biological conversion of syngas and hydrogen in biogas plants
}

\author{
Chaudhary Awais Salman ${ }^{*}, 1$, Sebastian Schwede ${ }^{1}$, Eva Thorin ${ }^{1,}$ Jinyue Yan ${ }^{1,2}$ \\ ${ }^{1}$ School of Business, Society, and Engineering, Mälardalen University, 883, SE-72 123 Sweden \\ ${ }^{2}$ School of Chemical Science and Engineering, Royal Institute of Technology, SE 10044 , Sweden
}

\begin{abstract}
Organic waste is a good source of clean energy. However, different fractions of waste have to be utilized efficiently. One way is to find pathways to convert waste into useful products via various available processes (gasification, pyrolysis anaerobic digestion, etc.) and integrate them to increase the combined efficiency of the process. The syngas and hydrogen produced from the thermal conversion of biomass can be upgraded to biomethane via biological methanation. The current study presents the simulation model to predict the amount of biomethane produced by injecting the hydrogen and syngas. Hydrogen injection is modelled both in-situ and ex-situ while for syngas solely the ex-situ case has been studied. The results showed that $85 \%$ of the hydrogen conversion was achieved for the ex-situ reactor while $81 \%$ conversion rate was achieved for the in-situ reactor. The syngas could be converted completely in the bio-reactor. However, the addition of syngas resulted in an increase of carbon dioxide. Simulation of biomethanation of gas addition showed a biomethane concentration of $87 \%$ while for hydrogen addition an increase of $74 \%$ and $80 \%$ for in-situ and ex-situ addition respectively.
\end{abstract}

\section{Introduction}

Waste biomass is an exclusive source of renewable energy and can be utilized in various ways like incineration, gasification, anaerobic or aerobic digestion. Anaerobic co-digestion of biodegradable municipal solid waste to produce biomethane is a proven technically feasible option[1]. However, the major challenge with source separated waste fractions is the significant amount of substrate with high ligno-cellulose content, which is not suitable for biodegradation under anaerobic conditions. Therefore, finding the alternate solutions for efficient utilization of different waste fractions is of importance. One of the options is to separate non-biodegradable waste, which is further converted by thermochemical processes such as pyrolysis, gasification, etc. for syngas production. The two processes i.e. anaerobic digestion and gasification/pyrolysis can be integrated to increase the efficiency of biogas plants, efficient utilization of various fractions of waste within one facility and decrease the complexity of carbon dioxide separation in the downstream processes [2]. The syngas $/ \mathrm{H}_{2}$

*corresponding author: chaudhary.awais.salman@mdh.se 
produced from these thermochemical processes can subsequently be converted to biomethane via biological methanation also known as methanogenesis process [3].

Biomethanation is the production of biomethane through biologically catalyzed reactions. Biological methanation is carried out by methanogenic archaea, which utilizes acetate or; carbon dioxide and hydrogen as a substrate [4]. Methanogens usually favor the conversion path of $\mathrm{CO}_{2}$ and $\mathrm{H}_{2}$ to methane and only methanogens are able to convert acetate to methane. The biological conversion of hydrogen is following the Sabatier reaction: $\mathrm{CO}_{2}+\mathrm{H}_{2} \rightarrow \mathrm{CH}_{4}+\mathrm{H}_{2} \mathrm{O}$ with the Gibbs free energy of $-131 \mathrm{~kJ} / \mathrm{mol}$ [5]. The conversion of hydrogen by biological Sabatier reaction can either be in-situ by introducing the hydrogen into an anaerobic digester or ex-situ i.e. in an external reactor with methanogens to favor the production of biomethane [4], [3].

The production of pure hydrogen is an energy intensive process either by hydrolysis of water or from thermochemical conversion, such as gasification or pyrolysis, of organic matter for example lingo-cellulosic biomass. The hydrogen can then be separated from the syngas containing $\mathrm{CO}, \mathrm{H}_{2}, \mathrm{CO}_{2}$ and $\mathrm{CH}_{4}$ by membrane separation of. The syngas itself can be used as a substrate for the biological conversion to biomethane [6]. The biological conversion of syngas can be carried out by a range of microorganisms which can simultaneously support the production of methane, hydrogen, and acetate [7]. Westman et al. [8] report that for the biological conversion of syngas through microorganisms can be carried out via two pathways with following six reactions with reaction $1 \& 2$ follow the $\mathrm{H}_{2} / \mathrm{CO}_{2}$ pathway:

$$
\begin{aligned}
& \mathrm{CO}+\mathrm{H}_{2} \mathrm{O} \rightarrow \mathrm{CO}_{2}+\mathrm{H}_{2}(\Delta \mathrm{G}=-20 \mathrm{~kJ} / \mathrm{mol}) \\
& \mathrm{CO}_{2}+4 \mathrm{H}_{2} \rightarrow \mathrm{CH}_{4}+\mathrm{H}_{2} \mathrm{O}(\Delta \mathrm{G}=-131 \mathrm{~kJ} / \mathrm{mol})
\end{aligned}
$$

The second pathway follows the conversion of $\mathrm{CO}$ to acetate followed by conversion of acetate to methane via following reactions [9].

$$
\begin{aligned}
& 4 \mathrm{H}_{2}+2 \mathrm{CO}_{2} \rightarrow \mathrm{CH}_{3} \mathrm{COOH}+2 \mathrm{H}_{2} \mathrm{O}(\Delta \mathrm{G}=-104 \mathrm{~kJ} / \mathrm{mol}) \\
& \mathrm{CH}_{3} \mathrm{COOH}+2 \mathrm{H}_{2} \mathrm{O} \rightarrow 4 \mathrm{H}_{2}+2 \mathrm{CO}_{2}(\Delta \mathrm{G}=95 \mathrm{~kJ} / \mathrm{mol}) \\
& 4 \mathrm{CO}+2 \mathrm{H}_{2} \mathrm{O} \rightarrow \mathrm{CH}_{3} \mathrm{COOH} \rightarrow \mathrm{CH}_{4}+\mathrm{CO}_{2}(\Delta \mathrm{G}=-176 \mathrm{~kJ} / \mathrm{mol}) \\
& \mathrm{CH}_{3} \mathrm{COOH} \rightarrow \mathrm{CH}_{4}+\mathrm{CO}_{2}(\Delta \mathrm{G}=-31 \mathrm{~kJ} / \mathrm{mol})
\end{aligned}
$$

\section{Model Development}

A number of authors have studied mathematical modeling of the biological conversion of syngas or hydrogen [10]-[13]. However, most of the modeling work is based on the development of a mathematical model for the biological methanation with the well-known ADM1 as the basis for these models [14]. Simulation of chemical processes gives detailed insights into the process streams and will be of great use for the further processing of information regarding the process. By considering these issues, this work is performed to develop the simulation of the process based on biochemical reactions instead of developing a mathematical model. Furthermore, a simulation model is established to predict the amount of biomethane from the anaerobic digestion and biological methanation process. The model is developed in Aspen Plus ${ }^{\circledR}$, which is a leading software for the development simulation models for various chemical processes [15]. The developed model can be incorporated with other thermochemical processes such as pyrolysis and gasification to measure the benefits and impact of integrating different processes.

Three cases have been considered for comparison. (a) In-situ hydrogen addition to the digester, (b) Ex-situ hydrogen addition in external bioreactor, and (c) Ex-situ syngas addition in the external bioreactor.

Process simulation for the anaerobic digestion is adopted from [16] and [17]. The model is selected because it can be incorporated in flowsheet based software such as Aspen Plus ${ }^{\circledR}$ with fewer complexities. The model can then be able to extend and integrate with different 
thermochemical processes such as pyrolysis and gasification. The model is originally developed to predict the biogas production from biodegradable substrates. The model is based on the biochemical reactions with first-order reaction kinetics and also includes the $\mathrm{pH}$-value and take ammonia inhibition into account. All the reaction kinetics and inhibitions are implemented into the Aspen Plus model through Fortran calculator blocks. The detail about all the chemical reactions used in the model can be found in [16], and the rate equations and their kinetic parameters are taken from [17]. The model predicts the biogas from the organic substrate by their carbohydrates, proteins, lipids and water content.

The model is then modified to introduce the hydrogen into the process. The design scheme for both in-situ hydrogen addition and ex-situ hydrogen addition is displayed in Figure 1. For in-situ upgrading of biogas, hydrogen is added in stoichiometric ratio i.e. 4 moles of hydrogen per each mole of $\mathrm{CO}_{2}$ present. The Sabatier reaction is added to the previous set of reactions. For the ex-situ processes, the digestate is separated into liquid and solid. The solid digestate with unconverted nutrients is utilized in the external reactor along with biogas from the digester and stoichiometric amounts of hydrogen. The reactions with their first order rate equations are added to the model to convert the hydrogen to biomethane biologically.

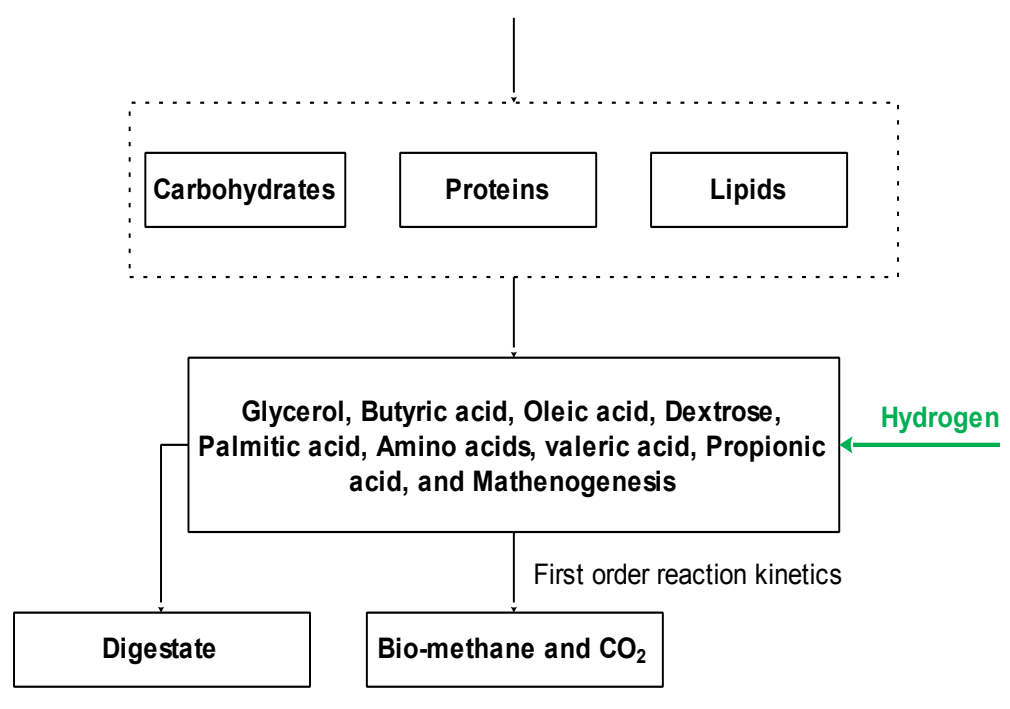

(a) 


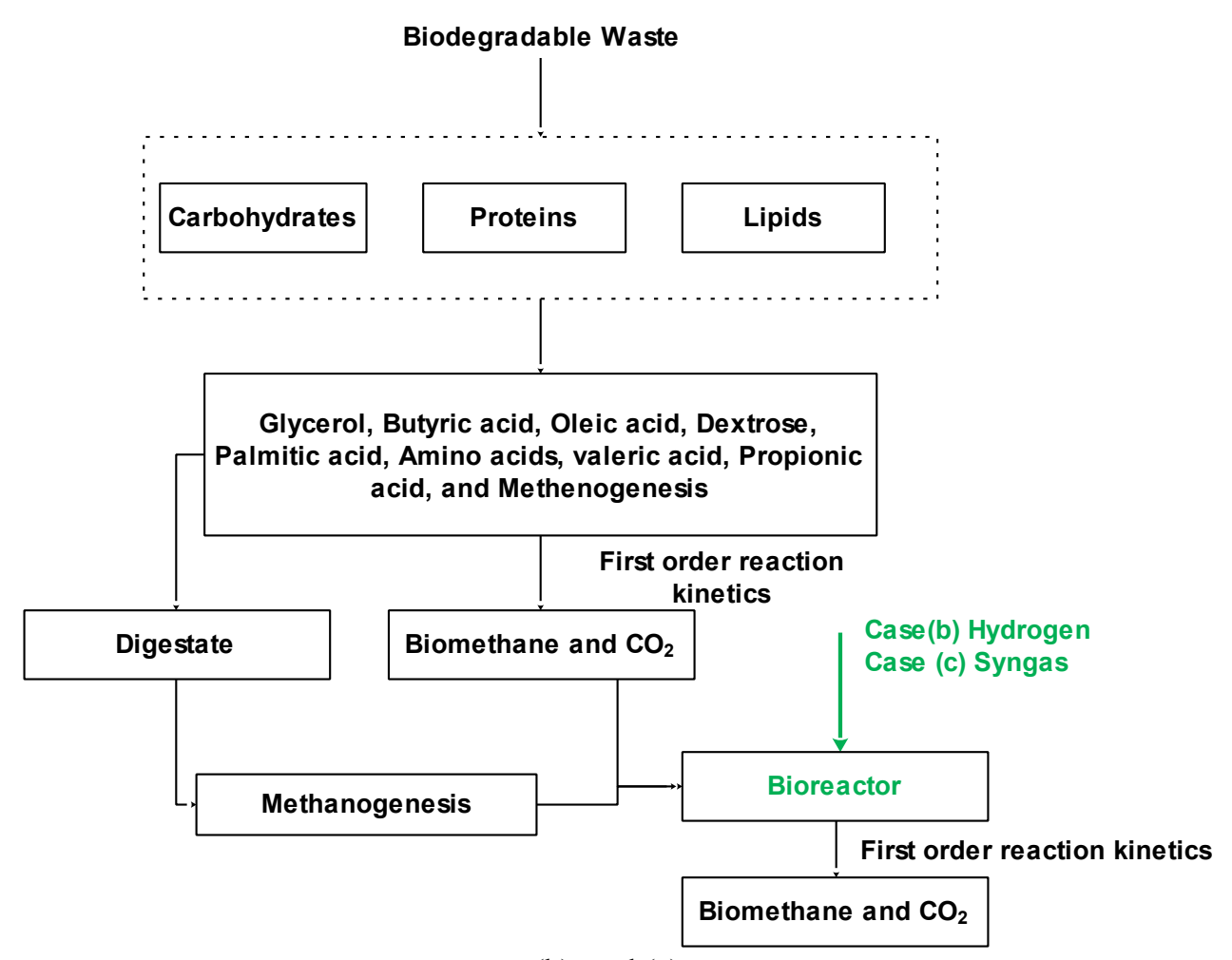

(b), and (c)

Figure 1: Scheme for designing the model and process simulation of anaerobic digestion with methanation of hydrogen (a) in-situ hydrogen addition (b) ex-situ hydrogen addition (c) Ex-situ syngas addition

For syngas addition to the bioreactor, the same modeling approach is used as described for ex-situ hydrogen addition in Figure 1 (b). Carbon monoxide is added in a stoichiometric amount of water present in the external bioreactor at a molar ratio of $1: 1$ and hydrogen to carbon dioxide mole ratio is $4: 1$ respectively. The organic composition of biodegradable waste used for the simulation of hydrogen and syngas methanation is presented in Table 1.

Table 1: Organic composition of biodegradable waste used for simulation

\begin{tabular}{llll}
\hline Organic composition of waste [18] & & \\
\hline Carbohydrates, \% & 50 & Moisture, $\%$ & 80 \\
Proteins, \% & 35 & Dry matter TS, \% & 20 \\
Lipids, $\%$ & 15 & VS (\% TS) & 66 \\
\hline
\end{tabular}

\section{Results}

The model for anaerobic digestion is validated with data taken from two plants and has been displayed in Table 2. Both plants are located in Sweden and run under mesophilic conditions. The primary substrate used in the Växtraft biogas plant is a source-separated organic municipal waste, and for Eskilstuna, the biogas plant is operated with waste sludge. The results obtained from the model are in agreement with the plant data. It should be noted that the organic composition of feed for the both biogas plants is assumed from the 
literature shown in Table 1. The actual composition may give different results for the process simulation.

Table 2: Difference between simulation results for anaerobic digestion and biogas plant data, taken from [19], [20].

\begin{tabular}{llllllc}
\hline & $\begin{array}{l}\text { Volume of } \\
\text { digesters, } \\
\mathbf{m}^{\mathbf{3}}\end{array}$ & $\begin{array}{l}\text { Feed, } \\
\text { t/y }\end{array}$ & $\begin{array}{l}\text { HRT, } \\
\text { days }\end{array}$ & $\begin{array}{l}\text { Methane } \\
\text { production, } \\
\text { MWh }\end{array}$ & $\begin{array}{l}\text { Simulation } \\
\text { results, } \\
\text { MWh }\end{array}$ & $\begin{array}{l}\text { Error, } \\
\%\end{array}$ \\
\hline $\begin{array}{l}\text { Växtraft biogas } \\
\text { plant }\end{array}$ & 4000 & 23000 & 20 & 15000 & 14641 & -2.38 \\
$\begin{array}{l}\text { Eskilstuna biogas } \\
\text { plant }\end{array}$ & 3600 & 72560 & 25 & 8603 & 9380 & 5.18 \\
\hline
\end{tabular}

Figure 2 shows the results obtained for the simulation of methanation of hydrogen. A stoichiometric amount of hydrogen i.e. 4 moles per each mole of carbon dioxide is added to both the in-situ and external reactor. The increase in biomethane concentration over the course of 30 days has been simulated. The results show that the concentration of biomethane will increase by the addition of hydrogen in both cases. However, the conversion of biomethane is faster in the case of the external methanation reactor. The final concentration of up to $80 \%$ biomethane is achieved for ex-situ conversion of hydrogen.

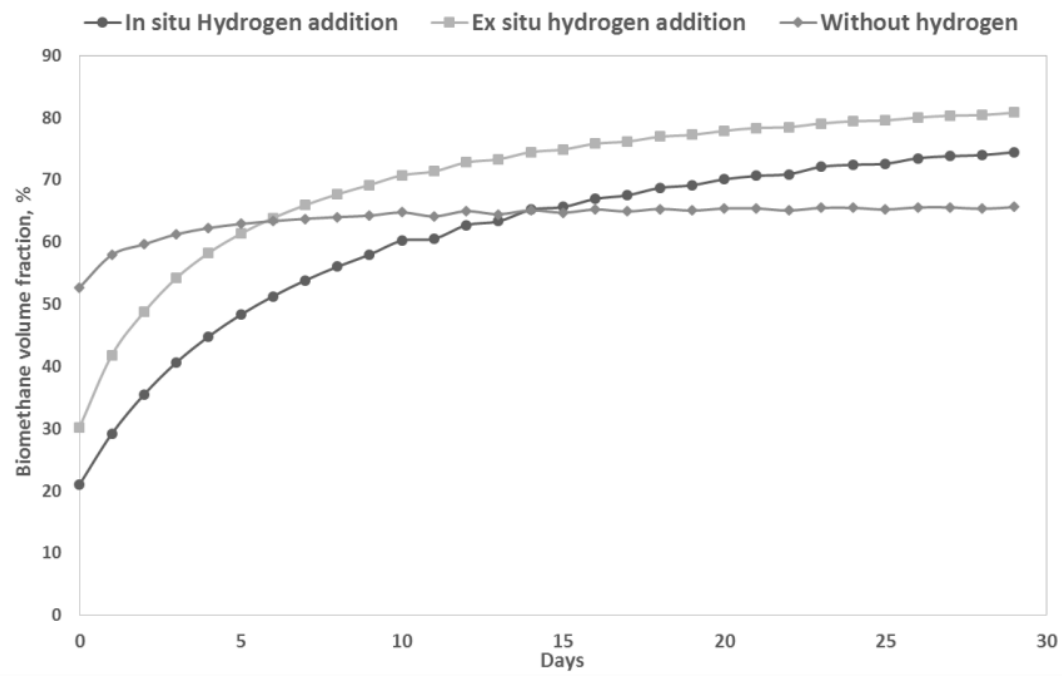

Figure 2: Change in biomethane concentration in biogas for all the cases (without hydrogen addition, hydrogen addition in the digester and external reactor)

Figure 3 displays the conversion of hydrogen for both cases. It can be seen that the model indicates that the hydrogen is not fully convertible via Sabatier reaction biologically. However, the conversion of hydrogen is higher in the case of the ex-situ biological reactor $(85 \%)$ after 30 days as compared to in-situ, where $80 \%$ of the supplied hydrogen was utilized. 


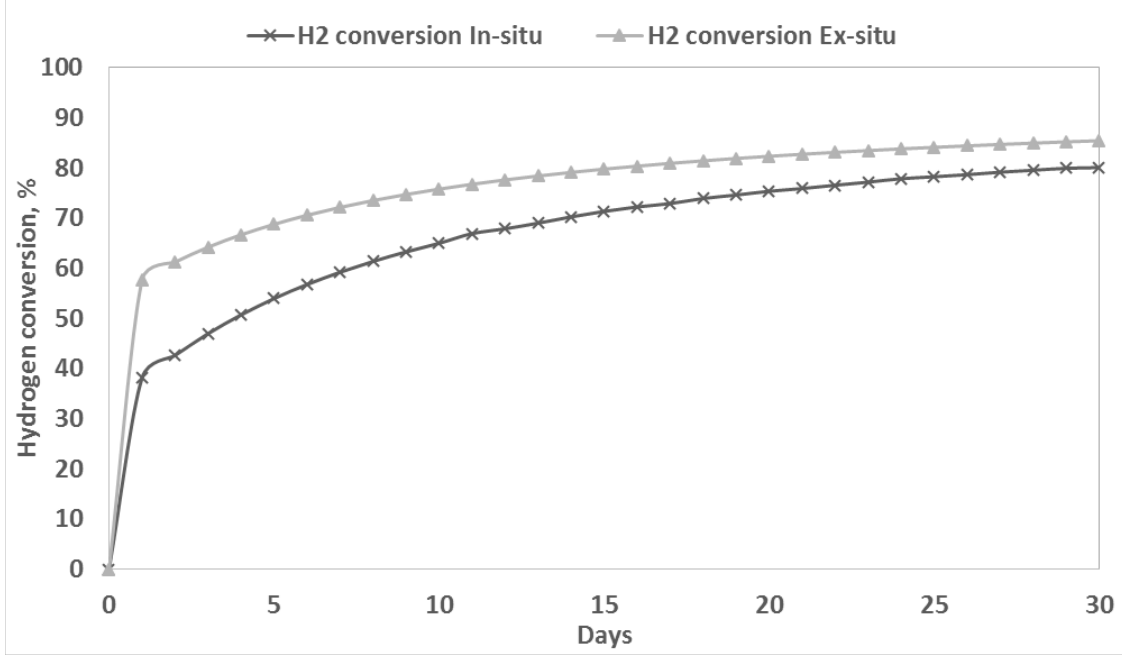

Figure 3: Conversion of hydrogen in the biological reactor

Figure 4 presents the change in volume fraction of biomethane with syngas addition. Initially, the simulation shows that a higher concentration of biomethane can be achieved by the addition of syngas as compared to the case with the addition of hydrogen. The model also indicates that the injection of syngas increases the concentration of biomethane as high as $95 \%$, but the concentration decreases and stabilizes around $87 \%$. This decrease is a result of the $\mathrm{CO}_{2}$ increase through reaction 5 and 6 , and also the incoming carbon dioxide with syngas also makes the final biogas slightly rich in $\mathrm{CO}_{2}$. The model also predicts that ex-situ syngas addition yields $13 \%$ more biomethane than ex-situ hydrogen addition and 23\% more biomethane than the in-situ addition of hydrogen.

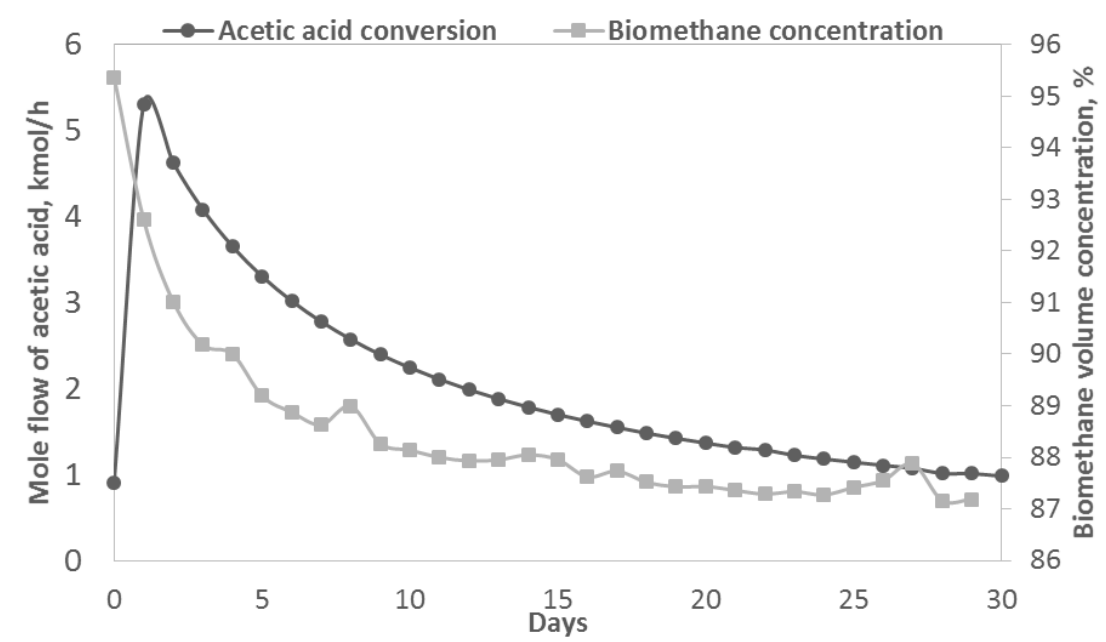

Figure 4: Biomethane volume fraction by biological conversion of syngas in Ex-situ reactor and Molar flow $(\mathrm{kmol} / \mathrm{h})$ of acetic acid by the addition of syngas in ex-situ reactor (Waste input of $3600 \mathrm{~kg} / \mathrm{h}$ )

The simulation of the biological conversion of syngas also shows the full conversion of hydrogen and carbon monoxide in the very beginning which indicates that the syngas utilization adopted to the acetogenic pathway for the biological conversion as described by reactions 3-6. The increase and conversion of acetic acid by the result of syngas addition is 
displayed in Figure 4. It can be seen that almost all the generated acetic acid from the syngas addition is converted to biogas.

\section{Discussion}

The in-situ upgrading of biogas offers a less complex option for biological methanation, but the process conditions have some limitations regarding the size of the digester, the production rate of $\mathrm{CO}_{2}$, and also requires thorough process design to inject the stoichiometric amount of hydrogen. Simulations for the above cases have been run for the Växtraft biogas plant. The biogas plant has an annual input of 23000 tons per year of organic waste with biomethane production capacity of $15000 \mathrm{MWh}$ annually [20]. The stoichiometric amount of hydrogen and syngas is injected into the process, and results are displayed in Figure 5. The results show that the biological methanation process can achieve $46-85 \%$ increase in biomethane.

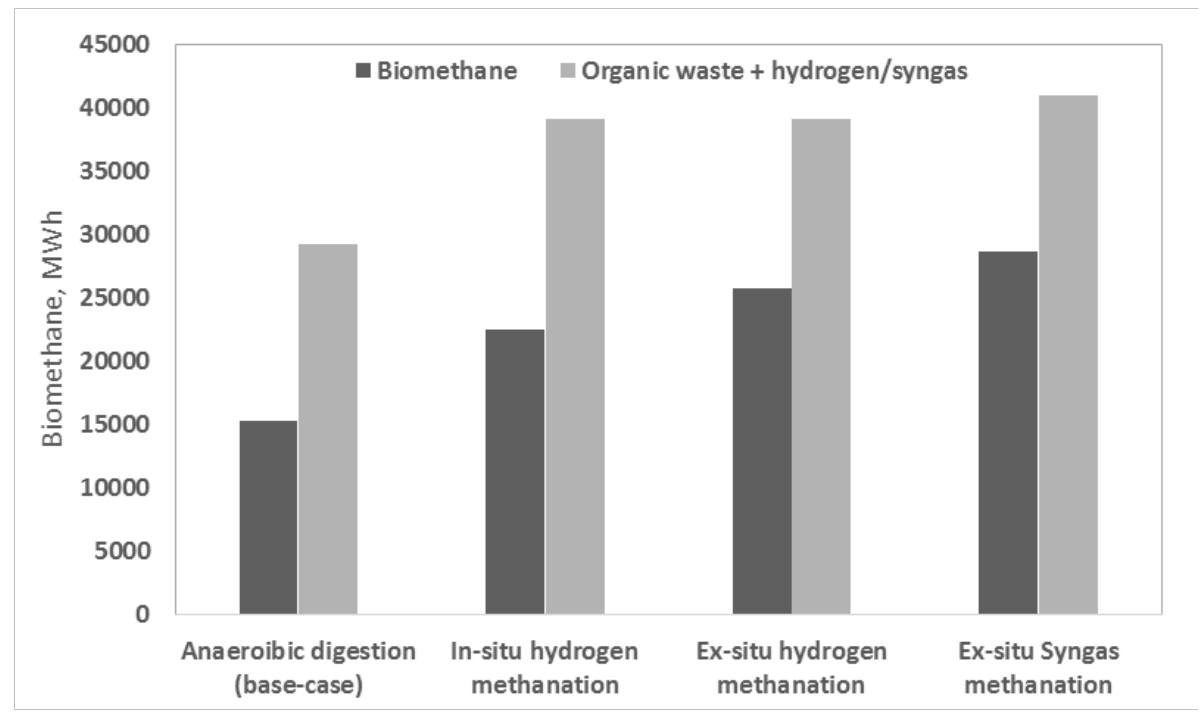

Figure 5: Increase in biomethane by biological methanation for a biogas plant

The increase is highly dependent on the amount of substrate i.e. hydrogen and syngas available for the process. Also, the production of hydrogen and syngas from thermochemical conversion processes are an energy intensive process and requires a significant amount of heat and power. Addition of hydrogen or syngas also affects the $\mathrm{pH}$ and buffer capacity due to the removal of $\mathrm{CO}_{2}$ from the liquid. Furthermore, the operation of an external biological reactor also requires work to setup and maintain a stable-running process. Hence, comprehensive process integration must have been carried out to evaluate the technical feasibility of thermochemical and biochemical process integration.

\section{Conclusion}

A simulation study of biological methanation of syngas and hydrogen was performed in this work for both ex-situ and in-situ bioreactor configurations. Highest conversion of hydrogen and syngas was achieved in ex-situ or separate methanation reactors as compared with the in-situ process. 


\section{References}

1. G. M. Guebitz, A. Bauer, G. Bochmann, A. Gronauer and S. Weiss, Biogas sci \& Tech, (2015)

2. C. Awais, S. Schwede, E. Thorin and J. Yan, E.Procedia (2017), (To be published)

3. G. Luo and I. Angelidaki, Biotechnol. Bioeng. 109, 2729-2736 (2012).

4. A. J. Guneratnam, E. Ahern, J. A. FitzGerald, S. A. Jackson, A. Xia, A. D. W. Dobson and J. D. Murphy, Bioresour. Technol. 225, 308-315 (2017)

5. G. Leonzio, Chem. Eng. J. 290, 490-498 (2016)

6. K. T. Klasson, M. D. Ackerson, E. C. Clausen and J. L. Gaddy, Enzyme Microb. Technol. 14, 602-608 (1992)

7. K. T. Klasson, B. B. Elmore, J. L. Vega, M. D. Ackerson, E. C. Clausen and J. L. Gaddy, Appl. Biochem. Biotechnol. 24-25 (1990)

8. S. Westman, K. Chandolias and M. Taherzadeh, Fermentation 2 (2016)

9. S. S. Navarro, R. Cimpoia, G. Bruant and S. R. Guiot, Front. Microbiol. 7 (2016)

10. A. Bensmann, R. Hanke-Rauschenbach, R. Heyer, F. Kohrs, D. Benndorf, U.

Reichl and K. Sundmacher, Appl. Energy 134, 413-425 (2014)

11. L. Jürgensen, E. A. Ehimen, J. Born and J. B. Holm-Nielsen, Bioresour. Technol. 178, 323-329 (2015)

12. M. K. Nikoo and N. A. S. Amin, Fuel Process. Technol. 92, 678-691 (2011)

13. I. Tilla and E. Dace, Energy Procedia 95, 475-481 (2016)

14. D. J. Batstone, J. Keller, I. Angelidaki, S. V Kalyuzhnyi, S. G. Pavlostathis, A. Rozzi, W. T. M. Sanders, H. Siegrist and V. A. Vavilin, Water Sci. Technol.45, 6573 (2002)

15. “Aspentech.” [Online]. Available: http://www.aspentech.com/. Accessed: (2016)

16. K. Rajendran, H. R. Kankanala, M. Lundin and M. J. Taherzadeh, Bioresour. Technol. 168, 7-13 (2002)

17 I. Angelidaki, L. Ellegaard and B. K. Ahring, Biotechnol. Bioeng. 63, 363-372 (1999)

18. U. Sonesson and H. Jönsson, Urban biodegradable waste amount and compostiion Case study Uppsala (1996).

19. E. Nordlander, J. Holgersson, E. Thorin, M. Thomassen and J. Yan, Int. Conf. Appl. Energy 1661-1675 (2011)

20. S. R. Esteves, Västerås ( Växtkraft ) Biogas Plant CASE STUDY - Source Segregated Biowastes, (2007). 